\title{
Disclosing and concealing: internet governance, information control and the management of visibility
}

\author{
Mikkel Flyverbom \\ Department of Intercultural Communication and Management, Copenhagen Business School, \\ Denmark,mfl.ikl@cbs.dk
}

Published on 30 Sep 2016 | DOI: 10.14763/2016.3.428

\begin{abstract}
The ubiquity of digital technologies and the datafication of many domains of social life raise important questions about governance. In the emergent field of internet governance studies, most work has explored novel governance arrangements, institutional developments and the effects of interactions among public and private actors in the emergence of the internet as a matter of concern in global politics. But the digital realm involves more subtle forms of governance and politics that also deserve attention. In this paper, I suggest that the 'ordering' effects of digital infrastructures also revolve around what I term the 'management of visibilities'. Drawing on insights from science and technology studies and sociologies of visibility, the paper articulates how digital technologies afford and condition ordering through the production of visibilities and the guidance of attention. The basic tenet of the argument is that there is an intimate relationship between seeing, knowing and governing, and that digitalisation and datafication processes fundamentally shape how we make things visible or invisible, knowable or unknowable and governable or ungovernable. Having articulated this conceptual argument, the article offers a number of illustrations of such forms of ordering.
\end{abstract}

Keywords: Internet governance, Science and technology studies (STS), Sociology, Datafication, Visibilities

\section{Article information}

Received: 25 Apr 2016 Reviewed: 17 Jun 2016 Published: 30 Sep 2016

Licence: Creative Commons Attribution 3.0 Germany

Competing interests: The author has declared that no competing interests exist that have influenced the text.

URL:

http://policyreview.info/articles/analysis/disclosing-and-concealing-internet-governance-information-c ontrol-and-management

Citation: Flyverbom, M. (2016). Disclosing and concealing: internet governance, information control and the management of visibility. Internet Policy Review, 5(3). https://doi.org/10.14763/2016.3.428

This paper is part of Doing internet governance, a special issue of Internet Policy Review guest-edited by Dmitry Epstein, Christian Katzenbach, and Francesca Musiani. 


\section{INTRODUCTION}

The ubiquity of digital technologies and the datafication of many domains of social life raise important questions about governance. Not so long ago, digital technologies were mainly seen as 'devices of information' and not 'agencies of order' (Peters, 2015), but this has certainly changed over the last decade. As processes of digitalisation and 'datafication' (Mayer-Schönberger and Cukier, 2013) come to shape most societal domains, it makes less and less sense to think of digital technologies as tools or as separate (cyber)spaces. Digital transformations increasingly make headlines, define political agendas and shape research priorities. In research circles, the nexus between digital technologies and governance - whether in the shape of (technical) coordination, (political) regulation or (social) ordering (Hofmann, Katzenbach, and Gollatz, 2016) - has emerged as a key concern and laid the foundation for the field of internet governance and more recent discussions of the role of data and algorithms in the social and political affairs (boyd and Crawford, 2012; Gillespie, 2014).

Scholarly work on internet governance has had a rapid and remarkable trajectory in trying to keep up with technological and political developments in this area. This research emerged as a set of reflections on technology and ideology offered from within the engineering labs and closeknit communities developing the technological innovations that we have come to know as the internet (Hafner and Lyon, 1996). As these technological developments spilled into more public, global contexts, internet governance research became occupied with questions about international agreements, participation, rights and related questions, primarily by engaging insights from international relations and political science (DeNardis, 2014; Mueller, 2010). As this paper suggests, we stand at the threshold of yet another major transformation when it comes to the role of digital technologies in societal and political affairs, which requires that internet governance scholars once again calibrate the conceptual tools and analytical approaches used to guide their work. At this point, questions about the entanglement of technology and social practices and the ordering effects of processes of digitalisation and datafication deserve more attention, and this requires that we extend the emerging engagement with insights from sociology and science and technology studies (STS). In particular, I suggest that internet governance research needs to explore how digital, datafied infrastructures afford and condition ordering through information control, the management of visibilities and the guidance of attention. Articulating the central role of visibility practices, such as transparency, surveillance, secrecy and leakages, in the digital age, this paper sets an agenda for internet governance research that makes processes of seeing, knowing and ordering central. To this end, the paper suggests a conceptual vocabulary for studying information control and managed visibilities as forms of ordering, and provides some empirical illustrations of such studies.

The paper makes two contributions to the emergent engagement with STS and sociological perspectives in internet governance research and work on the societal and political ramifications of digital technologies in political science more broadly. The first contribution is an overview of developments in the internet domain that make it pertinent to push beyond existing orientations and theoretical approaches. This takes the shape of a historical overview of the trajectory of internet governance research, with particular focus on the underlying assumptions about the internet, the primary objects of study, and the conceptions of governance reflecting different theoretical and disciplinary foundations.

In the field of internet governance, most work has explored governance arrangements, institutional developments and the effects of interactions among public and private actors in the 
emergence of the internet as a matter of concern in global politics (DeNardis, 2009; 2014; Deibert et al, 2010; Mueller, 2010). For anyone trying to understand the public, political and scholarly significance of the internet, these works have been ground-breaking and central to the emergence of this field of research, as well as the public understanding of the importance of the issues. But to push our field forward, we need more theories, analytical vocabularies and empirical orientations that take into account how digital and datafied infrastructures are ingrained in and shape social and cultural practices that go beyond what is normally associated with internet governance (such as regulatory bodies, standard-setters and technical communities) and are central to a much wider range of ordering processes (for similar arguments, see for instance Flyverbom, 2011; Mansell, 2012; Franklin, 2013; Musiani, 2015).

The second contribution of the paper is to articulate what science and technology studies and, in particular, sociologies of knowledge and visibility (Shapiro, 2003; Brighenti, 2007; Rubio and Baert, 2012; Flyverbom et al., 2016) have to offer when it comes to investigating how digital technologies relate to governance. It suggests, in particular, that a focus on the dynamics and effects of information control and visualisation is a valuable starting point, and provides some empirical illustrations of what may be gained by approaching internet governance issues in this manner. Focusing on information control and the management of visibilities may open up new avenues for research and make different objects of analysis central, in particular when it comes to understanding the role of digital infrastructures in the shaping of social and political realities. As suggested by Gillespie (2016), we still lack "the language to capture the kind of power" that digital infrastructures involve, so we need to explore alternative conceptualisations and analytical vocabularies that can invigorate studies and theories of digital technologies in new and exciting ways.

\section{EARLY TRAJECTORIES OF INTERNET GOVERNANCE RESEARCH}

Even though early discussions of the internet often considered it to be a separate space outside the reach of traditional forms of governmental regulation - for instance by referring to it as 'cyberspace', important scholarship has shown that it has always been subjected to multiple forms of governance (Lessig, 1999; Goldsmith and Wu, 2006; Musiani et al., 2016). Studies of internet governance emerged alongside the technological developments they set out to investigate and were entangled with the people, organisations and ideologies shaping this domain. That is, many of those pursuing research on internet governance were also so-called 'inter-nauts', i.e., members of the technical communities building and coordinating the internet and/or directly involved in policy development in this area. Reflecting this symbiosis, early scholarly discussions were focused on technical and operational issues (Ziewitz and Pentzold, 2014), and often made technical arguments for policy approaches, such as the need for the governance of technological networks itself to be networked (Klein, 2002; Kleinwächter, 2000). Most of this research focused on a narrow set of organisations, in particular the Internet Corporation for Assigned Names and Numbers (ICANN), and other bodies directly involved in standard-setting, coordination and other operational matters (Klein, 2002; Mueller, 2002).

These early discussions of internet governance had a strong focus on showing the uniqueness of the internet and how the (libertarian) logics underpinning its development conditioned particular forms of governance. These approaches suggested that the internet has a distinct decentralised technological architecture, which makes it difficult to govern, and focused on the 
tension between a decentralised, global technological innovation and established forms of regulation based on national boundaries and sovereignty. Such discussions often articulated a resistance to top-down control and governmental interventions, and a focus on open standards and other technical features that allow for interoperability, peer production, innovation and unimpeded data flows. To sum up, these early approaches to internet governance had a primary focus on technical coordination, individual organisations, the (libertarian) ideologies shaping the area, and conceptualised internet governance mainly as a matter of technical coordination to be kept separate and safe from statist regulation. These features served the purpose of establishing the internet as different from other technological developments, and to separate the internet from ordinary social and political life.

With commercialisation, intense political struggles, and the growing importance of the internet as an infrastructure for trade and socio-cultural formations, these orientations are no longer clear-cut or even pervasive, but they still form an important foundation for what remains a controversial and problematic relation between the internet and established, (inter)governmental approaches to governance.

As discussions of the internet and its consequences for economic, political and cultural developments grabbed the attention of the public, scholars and policymakers, also work on internet governance took on new challenges and themes. In particular, questions about processes of institutionalisation, inter-governmental arrangements and stakeholder participation, as well as policy issues such as privacy, security and rights, became more central.

The growing focus on the internet as a phenomenon with wide-reaching societal consequences was also reflected in the understandings of governance underpinning research in this emergent field. Moving beyond the focus on technical forms of coordination and operational bodies allowed for issues like the intersections between established statist and intergovernmental forms of regulation and more controversial multi-stakeholder approaches to be addressed (Anderson, Dean and Lovink, 2006; Mueller, 2010; Flyverbom, 2011). Also, this research highlighted the global nature of internet governance as an issue area with ramifications for a wide range of more established policy concerns (DeNardis, 2009). This involved linking the internet to questions of inclusion, development, rights and security (Chadwick, 2006; Jørgensen, 2006). In terms of how governance was arranged, this research highlighted that there was no institutionalised regulatory system in place, and few established authorities or international agreements like those we see in other areas. It also stressed the complexity of internet governance, where some parts are steered by a myriad of technical, private, standardsbased and other ad hoc forms of regulation, some parts are handled by established international organisations and others are addressed through more informal governance arrangements, such multi-stakeholder dialogues without negotiation- or decision-making power.

Reflecting the maturation of the internet and the growing focus on its 'governability' (Hofmann, Katzenbach and Gollatz, 2016), much of this research focused on the sites and organisations where internet governance was addressed, such as the World Summit on the Information Society and related bodies, and questions about participation and inclusion (Mueller, 2010; Singh and Flyverbom, 2016). Largely, internet governance research was born and bred in disciplinary fields with a focus on institutionalisation (what institutions and governance regimes are emerging to handle the global governance and politics of the internet?), the state (how do state and non-state actors coordinate or clash in this area and what are possible effects of public or private forms of governance?) and pragmatic politics (how is the internet emerging as a key asset and object of regulation?). This was also reflected in the theories underpinning 
this work, where most insights and conceptual approaches were adopted from the field of international relations and addressed issues such as the role of public and private actors, intergovernmental processes, networks and institutional developments.

A similar point is made by Hofmann, Katzenbach, and Gollatz (2016), who argue that the work we normally associate with internet governance has focused on regulation, which can be understood as institutionalised, deliberate and goal-oriented interventions by public or private actors seeking to shape behaviour, solve policy problems and implement rules. This is in some ways odd, since very influential work such as Lessig's exactly stressed the need to understand the regulation of the internet as an interplay among such different forces as laws, norms, markets, and architecture or technical codes (Lessig, 1999). This is partly due to disciplinary differences in theoretical and empirical orientation. But it is still puzzling that only little research has captured the relations among these four forms of governance, or offered analytical frameworks that may help us understand their entanglement (exceptions include Bowrey, 2005; Flichy, 2007; Mansell, 2012).

Taken together, these discussions articulated the need for intergovernmental negotiations and multi-stakeholder dialogues about the internet, and brought up important questions about inclusion, institutionalisation, and rights. Still, most work held on to the idea that the internet should be thought of as a separate space with a need for novel governance arrangements rather than extensions of statist approaches. But they served the important purpose of showing the importance of the internet for political affairs and the need for thorough research in this area. Building on these foundations while acknowledging their limitations is central when we move forward in attempts to grasp emerging developments and develop new vocabularies for the study of governance of and by digital technologies.

\section{DIGITAL INFRASTRUCTURES AND ORDERING - IN SEARCH OF NEW APPROACHES}

With the emergence of ubiquitous digitalisation and datafication (Mayer-Schönberger and Cukier, 2013), digital technologies have become infrastructures for large parts of social life and an increasing number of human activities take a digital form or leave extensive digital traces. By using digital technologies, we control global value chains and production processes, engage in politics and connect with friends and family. The infrastructures making all this possible consist of multiple digital platforms, tracking systems and other largely invisible ways of sourcing and aggregating data, as well as advanced algorithms and visualisation techniques. As digital technologies become ubiquitous, it seems that we need research that picks up new kinds of issues and discussions than those we normally associate with internet governance research. My suggestion is that we need to shift from the focus on how to govern digital transformations, 'the internet' or 'cyberspace' to the question of how these govern. The internet is not just an object of need in governance, but itself constitutive of governance - a means of ordering (Flyverbom, 2011; Ziewitz and Pentzold, 2014; Hofmann, Katzenbach, and Gollatz, 2016).

For scholars interested in the intersection of digital technologies and governance, basic sociological questions about the individual, organisational and societal ramifications of these developments should be central. That is, how do digital transformations shape fundamental issues and mundane practices, such as how we produce knowledge, how we decide what is important, and how we work and think. But most public discussions focus on more spectacular 
issues - the increasing financial resources of internet companies, concerns about states tracking and profiling citizens, and the effects of digital disruption on traditional industries and institutions. As a result, not enough work addresses the materiality and the possibilities for action offered by digital infrastructures and platforms. To the degree that we even think of their existence, such infrastructures come across as neutral or innocent, and we are more concerned with the interests and aims of the companies and other actors building and taking advantage of them. This focus means that we refrain from studying a wide range of issues that could be considered relevant for, and part, of internet governance. Also, from within the field, a number of scholars have called for more comprehensive and fine-grained accounts of the relations between digital technologies and governance, and the complex entanglements of public and private actors, humans and technologies (DeNardis, 2012; Musiani, 2015; Hofmann, Katzenbach, and Gollatz, 2016). At the core of this critique is an emergent realisation that governance involves mundane activities and forms of ordering that are overlooked if we focus too much on the role of formal institutions and deliberate attempts to regulate.

One way to rethink the meaning of internet governance is to conceptualise governance in terms of ordering, not regulation. To this end, insights from Foucauldian and related sociologies of governance are a useful starting point (Dean, 1999; Law, 2003). Such analytical vocabularies are more agnostic when it comes to explanations about causes and structures, more focused on addressing relational interactions, and more practice-oriented than traditional work on internet governance (see Flyverbom, 2011 for a more elaborate discussion). Such broadly sociological approaches increasingly mark discussions about uses, design, digital infrastructures, materiality and similar sociological accounts of digital transformations. Engaging with these more encompassing research agendas could help establish links and conversations across disciplines and phenomena of relevance to our field. The point is not only that we need to open up the concept of governance to include more subtle and emergent forms, but also that more attention to social practices and ordering processes highlights a set of discussions that have been marginal in previous work. A range of sociological perspectives and themes, like the ones discussed above, are relevant for this purpose.

As digital technologies and data become ubiquitous and infrastructural, so that it makes less sense to think of 'cyberspace' as a separate and independent space, we have to shift our attention to the more subtle and intricate ways they shape individual, organisational and societal possibilities for action. To this end, we need more accounts of what digital technologies are, afford and do when it comes to shaping practices, interactions and visibilities. These more subtle forms of ordering that digital technologies create are also forms of internet governance and need to be included in our conceptual approaches (Hofmann, Katzenbach, and Gollatz, 2016: 7).

\section{STUDIES OF ORDERING: INFORMATION CONTROL AND THE MANAGEMENT OF VISIBILITIES}

Insights from sociology and science and technology studies are useful starting points if we want to reinvigorate studies of internet governance. What I aim to do here is to stress how sociological accounts of visibility (Brighenti, 2007; 2010) have a lot to offer when it comes to articulating how digital technologies facilitate and constrain our possibilities for action. Visibility, information control and knowledge are central aspects of power and governance, and deserve more scrutiny, particularly in the age of big data, autonomic computing and radical 
transparency. Novel studies of ordering could start exploring how digital transformations shape the way we see, know and govern. This extended research agenda for internet governance studies would make questions about information control and visibility management central, and study how processes of digitalisation and datafication contribute to ordering by making certain phenomena and practices visible, and others invisible, in ways that come to guide our attention and contribute to social and political ordering. Drawing on insights from science and technology studies, affordance theory and sociology, such approaches help us grasp how digital technologies afford and condition ordering through the production of visibilities and the guidance of attention. The argument that there is an intimate relationship between seeing, knowing and governing (Foucault, 1988; Brighenti, 2007) deserves further scrutiny because digitalisation and datafication fundamentally shape how we make things visible or invisible, knowable or unknowable and governable or ungovernable. Some work on the use of digital technology has engaged with questions about visibilities and invisibilities (Treem and Leonardi, 2013) and with questions of transparency (Weber, 2008), but without considering it as a part of the broader governance effects of digital technologies. I suggest that a more extensive focus on visibilities invites us to explore how digital technologies condition ordering, and how our attention is guided as a result of these dynamics. That is, systems of governance or forms of ordering always revolve around particular ways of seeing and perceiving, involve distinctive ways of thinking and questioning and work through concrete practical rationalities and techniques of intervention (Foucault, 1988; Dean, 1999).

All types of knowledge production and visualisation techniques have implications for what we see as important and possible to govern, and to unpack these we can rely on conceptual discussions of affordances and the material foundations of knowledge production (Hutchby, 2001; Leonardi, 2012; Hansen and Flyverbom, 2015). Such approaches invite us to engage with questions about the material infrastructures and sources of data that are used for purposes of governance, about the political rationalities that digital technologies help institutionalise, and the patterns of exclusion and inclusion involved when social processes and phenomena are made 'algorithm-ready' (Gillespie, 2014; Madsen et al., 2016). The affordances of digital technologies when it comes to ordering can be explored at the individual, organisational and societal level, and the following section offers three examples.

\section{GOVERNING THROUGH VISIBILITIES}

Having articulated the conceptual argument, let me offer some illustrations of the possible shape of such studies. As suggested by Walters (2012: 52), we need to explore the "new territories of power" associated with "the entanglement of the digital, the informational and the governmental". As stressed above, there are many valuable ways to explore such encompassing questions about how digital technologies govern and are governed, and how ordering plays out as a result of digital transformations. Even if we focus on information control and visibilities, the list of possible topics is extensive, and cuts across individual, organisational, material and societal levels of analysis. In this context, I can only hint at a couple of these, and the following three suggestions are in no way exhaustive. But I hope they illustrate some of what could be explored by engaging these ideas about information control and visibilities in future research.

\section{TRANSPARENCY REPORTS}

One question is how our understanding of the phenomenon 'internet governance' is conditioned by the kinds of information and disclosures that make it visible and knowable in the first place. 
As noted above, internet governance plays out in a bewildering range of settings, involves multiple actors and encompasses both intergovernmental, private and technical forms of governance. But we rarely think about how these processes are about managing visibilities in ways that condition particular forms of ordering. One emergent form of internet governance is what internet and telecommunications companies refer to as 'transparency reports' and related attempts to show how powerful actors seek to control digital spaces. These reports disclose what data companies compile, the requests for information that states make, and how states filter and sometimes shut off the internet. Such reports thereby respond to an increased focus on transparency when it comes to data aggregation, covert uses of data, as well as filtering, surveillance and censorship in digital infrastructures. But they also distract our attention from the roles and responsibilities of internet companies. Transparency reports may list the number of requests made by individual governments, but they do not provide insight into the agreements or relationships between states and internet companies. They are also a very particular kind of reporting, which may cater to demands for openness and disclosure about government surveillance and censorship, but provide a very specific response in a preformatted and selective shape. What is particularly significant in this context is that transparency reports seek to articulate the value of numbers-based approaches to governance, and challenge (what internet companies consider to be) the overly emotional reactions that policymakers often rely on (Flyverbom, forthcoming). Attempts to make digital technologies governable by use of data visualisations - such as transparency reports - are important to investigate because they select and visualise information in ways that are neither natural nor innocent, and thus manage visibilities and guide our attention.

The result of these disclosures in the name of transparency is that the public gaze is directed to particular parts of the problem - for instance that some governments make a lot of requests for information to be taken down or made available for their use. But it also important to remember that some states are not even part of such reports because they refuse to share this information. Also, we must not forget that internet companies are involved in other forms of data control and data sharing that they do not talk about publicly, and we can think of transparency reports as strategic ways of guiding our attention. For instance, it was only after the Snowden revelations that Google made it clear that its transparency reports had not disclosed information on how the company feeds information about users to the National Security Agency (NSA). As Google mentioned somewhat apologetically in a blog post: "U.S. law does not allow us to share information about some national security requests that we might receive. Specifically, the U.S. government argues that we cannot share information about the requests we receive (if any) under the Foreign Intelligence Surveillance Act. But you deserve to know" (Google official blog, 2013, para. 3). Because transparency reports are voluntary and initiated by companies themselves, the content and format can be selective enough to allow for such limitations to stay out of sight. As a result, it is often not clear what data is selected and omitted in these reports are compiled and we are rarely given insight into the contexts and conditions of their production. Transparency reports are also a form of obfuscation and strategic opacity (Stohl, Stohl, and Leonardi, 2016). But my argument is not simply that such reports should be more inclusive and deliver more actual transparency, but also that all kinds of disclosures guide our attention and must be understood as managed visibilities that could be different. That is, they invite us to understand internet companies and governance issues in certain ways. This is also what my second illustration highlights.

\section{INTERNET PLATFORMS, HUMANS AND MACHINES}

Internet platforms like Google, Twitter and Facebook are often perceived as different from traditional companies, and they curate this position quite carefully, for instance by stressing 
organisational values like dialogue, transparency and innovation (Flyverbom, 2015). But most of the time, we only know and engage with these companies through the services they provide search, connecting with friends or possibilities for discussion. With no products of their own and their focus on facilitating interactions and sharing, they come across as utilities and platforms rather than normal companies. This position serves an important purpose and is actively maintained by their owners and directors. To the degree that such platforms are seen as technical utilities, not complex organisations full of people and engaged in strategic attempts to shape political agendas and cultural formations, they are in a better position to stay off the radar when it comes to regulation and oversight.

Recent discussions of how Facebook Trending relies not only on neutral and consistent algorithms, but also human curators who seemingly highlight some news stories and political views over others, has shown what happens if we start to think of internet companies as similar to news conglomerates. We have a long history of regulating the latter very strictly, and falling into a similar category would put a company like Facebook in a very different situation than at present. The strategic positioning as utilities involves issues such as human labour, how digital data is organised and edited and how internet companies relate to culture and politics. My point is that these issues should be part of our focus when we investigate how the internet is governed and shapes governance. The task is mainly to establish the links between internet governance and emergent and important research on, for instance, how human labour is invisible on internet platforms, how digital technologies condition particular forms of knowledge production, how identities and personal information are curated in digital spaces and how algorithmic operations edit, sort and shape realities. Starting points could be work on the societal implications of algorithms and data (Gillespie, 2014; Flyverbom and Madsen, 2015; Pasquale, 2015), and studies of digital labour and the entanglement of human and technical operations at work on internet platforms (Irani, 2015; Roberts, 2016). These may seem to be only remotely relevant to internet governance studies, but the links are important to explore. As I have suggested in this section, what is made visible by and on internet platforms has consequences for how they are perceived and regulated, and how we think of digital transformations more broadly. But questions of visibilities and their relation to ordering are important to explore not only at the organisational level, but also as they shape individual conduct and create the foundation for how we govern societal affairs.

\section{DATA DOUBLES}

Digital technologies and data also play important roles in the production of visualisations that we use as the basis for decisions and governance. At the individual level, an example is what Ruppert (2011) and others have referred to as 'data doubles', i.e. the sum of digital traces we leave. As data doubles come to function as complete representations of us in the context of governance, we see the emergence of potentially worrying scenarios, including the possibility of predictive policing and other forms of governance that do not rely anymore on situated encounters with the subjects they seek to govern (Hansen and Flyverbom, 2015). Beyond the level of the individual, digital transformations also shape areas like urban governance (Kitchin, 2014), the prevention of terrorism (Morozov, 2014b), control with financial transactions (Hansen and Flyverbom, 2015), and international development (Hilbert, 2013). Digitalisation and datafication have implications for how we approach societal challenges, such as terrorism, development or tax evasion. A focus on the management of visibilities invites us to consider how such regulatory or political issues come to look different as a result of digital transformations. In the case of development or tax evasion, the reliance on digital, datafied infrastructures means that established ways of producing knowledge are challenged and supplemented by algorithmic forms of calculation and scrutiny. That is, whereas development agencies usually rely on 
national statistics or household surveys, the use of digital traces as indicators of food crises or epidemics produces rather different types of visualisation and knowledge, direct our attention to new issues, and lead to alternative ways of dealing with governance issues (Flyverbom and Madsen, 2015). The point is not that big data produce more accurate 'truths', but rather that we need to explore how such forms of knowledge production condition different and sometimes problematic approaches to governance (Madsen et al., 2016). Morozov (2014b) uses the example of terrorism. In the past, and using more traditional forms of knowledge and visualisation, this was considered a problem with strong ties to history and foreign policy. But if we approach terrorism by use of digital technologies and the aggregation of digital traces, terrorism takes the shape of an 'information problem' - a matter of picking up enough signals to pre-emptively strike against a (soon to become) terrorist. Morozov's focus is on the problematic, technocratic effects of these forms of what he terms 'algorithmic regulation' based on 'Silicon valley logics'. Even if we do not share Morozov's worries, it is important to explore how digital technologies and datafication unsettle "key questions about the constitution of knowledge, the processes of research, how we should engage with information, and the nature and categorization of reality" (boyd and Crawford, 2012: 665). In particular, we need to consider how political controversies and complex governance issues are re-articulated as administrative or technical matters, and to reflect on the consequences of such 'post-political' forms of governance (Garsten and Jacobsson, 2013). The example of terrorism suggests how ubiquitous digital technologies and processes of datafication create new conditions for how we see, know and govern the world around us. With this, I have sought to illustrate that digital technologies come to shape the way we manage visibilities and produce knowledge, and that these formations have consequences for how we make the world around us knowable and governable. Such questions are not foreign to sociological and STS-inspired accounts of digital transformations, but are rarely considered part of the field of internet governance.

\section{CONCLUSION}

This paper has suggested that contemporary developments in the digital domain invite us to extend and reinvigorate studies of internet governance by giving more attention to questions of managed visibilities and their relation to processes of ordering. Through encounters with sociology, science and technology studies and similar approaches, we have seen a growing interest in more encompassing approaches to governance, extending far beyond Lessig's (1999) call for approaches to internet governance that address both legal and technical forms of governance. In contrast to the focus on regulation in most internet governance studies, such accounts approach governance by focusing on the forms of ordering (Flyverbom, 2011) and mundane coordination activities (Hofmann, Katzenbach, and Gollatz, 2016) involved, the 'relevance' of algorithms for social and political formations (Gillespie, 2014; Ziewitz, 2016) and the role of infrastructures and architectures in the shaping of conduct (DeNardis, 2012). These approaches allow for far more elaborate and fine-grained investigations of how digital technologies and datafication processes become woven into the fabric of social life. But the digital realm also involves other subtle forms of governance that deserve attention. In particular, I have sought to articulate how discussions of the relation between information control, visibilities and governance could move the field forward, and the concern with seeing, knowing and governing could pave the way for novel studies of internet governance. To this end, the concept of managed visibilities is a starting point that invites us to explore how digitalisation and datafication condition particular forms of information control and the guidance of attention. The conceptual and illustrative discussions of ordering through the management of 
visibilities show both how the increasingly ubiquitous and infrastructural nature of digital technologies shapes societal and political transformations, and how such theoretical approaches may contribute to the opening up of exciting new avenues for research in and beyond the field of internet governance studies. These contributions are important because they may help us reflect on the largely invisible ways in which digital infrastructures and architectures institutionalise and normalise particular forms of seeing, knowing and governing. 


\section{REFERENCES}

Anderson, J., Dean, J. \& Lovink, G. (2006). Reformatting Politics: Information Technology and Global Civil Society. London: Routledge

Bowrey, K. (2005). Law and internet cultures. Cambridge, UK; New York, N.Y: Cambridge University Press.

boyd, d., \& Crawford, K. (2012). Critical questions for big data: Provocations for a cultural, technological, and scholarly phenomenon. Information, Communication \& Society, 15(5), 662-679. doi:10.1080/1369118X.2012.678878

Brighenti, A. (2007). Visibility: A Category for the Social Sciences. Current Sociology, 55(3), 323-342. doi:10.1177/0011392107076079

Chadwick, A. (2006) Internet Politics: States, Citizens, and New Communication Technologies. Oxford: Oxford University Press

Clinton, B. (2000, March 8). Address by Bill Clinton at John Hopkins University re: Permanent Normal Trade Relations Status for China. Retrieved from http://www.techlawjournal.com/cong106/pntr/20000308sp.htm

Dean, M. (1999) Governmentality: Power and Rule in Modern Society. London: Sage.

Deibert, R., Palfrey, J., Rohozinski, R., \& Zittrain, J. (Eds.). (2008). Access denied: the practice and policy of global Internet filtering. Cambridge, Mass: MIT Press. Available at https://mitpress.mit.edu/books/access-denied

Deibert, R., Palfrey, J., Rohozinski, R., \& Zittrain, J. (Eds.). (2010). Access controlled: the shaping of power, rights, and rule in cyberspace. Cambridge, Mass: MIT Press. Retrieved from https://mitpress.mit.edu/books/access-controlled

DeNardis, L. (2009). Protocol Politics: The Globalization of Internet Governance. Cambridge, Mass: MIT Press. doi:10.7551/mitpress/9780262042574.001.0001

DeNardis L. (2012) Hidden levers of Internet control. Information, Communication \& Society, 15(5), 720-738. doi:10.1080/1369118X.2012.659199

DeNardis, L. (2014) The Global War for Internet Governance. New Haven: Yale University Press.

Flichy, P. (2007). The Internet Imaginaire. Cambridge, Mass: MIT Press.

Flyverbom, M. (2011) The Power of Networks: Organizing the Global Politics of the Internet. Cheltenham: Edward Elgar.

Flyverbom, M. (2015). Sunlight in cyberspace? On transparency as a form of ordering. European Journal of Social Theory, 18(2), 168-184. doi:10.1177/1368431014555258

Flyverbom, M. (in press). Corporate advocacy in the internet domain: Shaping policy through data visualizations. In C. Garsten \& A. Sörbom (Eds.), Power, policy and profit: corporate engagement in politics and governance. Cheltenham, UK; Northampton, MA, USA: Edward Elgar Publishing. 
Flyverbom, M., \& Madsen, A. K. (2015). Sorting data out: unpacking big data value chains and algorithmic knowledge production. In F. Süssenguth (Ed.), Die Gesellschaft der Daten: über die digitale Transformation der sozialen Ordnung (pp. 123-144). Bielefeld: Transcript.

Flyverbom, M., Leonardi, P., Stohl, C., \& Stohl, M. (2016). The Management of Visibilities in the Digital Age: Introduction to special issue. International Journal of Communication, 10. Retrieved from http://ijoc.org/index.php/ijoc/article/view/4841

Franklin, M. I. (2013). Digital Dilemmas: Power, Resistance, and the Internet. Oxford: Oxford University Press.

Garsten, C., \& Jacobsson, K. (2013). Post-political regulation: soft power and post-political visions in global governance. Critical Sociology, 39(3), 421-7. doi:10.1177/o896920511413942

Gillespie, T. (2014). The relevance of algorithms. In T. Gillespie, P. J. Boczkowski, \& K. A. Foot (Eds.), Media Technologies: Essays on Communication, Materiality, and Society. Cambridge, MA: MIT Press. Available at http://culturedigitally.org/2012/11/the-relevance-of-algorithms/

Gillespie, T. (2016, May 18). Algorithms, clickworkers, and the befuddled fury around Facebook Trends [Blog post]. Retrieved September 28, 2016, from

http://culturedigitally.org/2016/05/facebook-trends/

Hafner, K., \& Lyon, M. (1996). Where Wizards Stay Up Late: The Origins of the Internet. New York: Simon \& Schuster.

Hansen, H. K., \& Flyverbom, M. (2015). The politics of transparency and the calibration of knowledge in the digital age. Organization, 22(6), 872-889. doi:10.1177/1350508414522315

Hutchby, I. (2001). Texts, Technologies and Affordances. Sociology, 35(2), 441-56.

doi:10.1017/Soo38038501000219

Foucault, M. (1988). Power/knowledge: Selected interviews and other writings, 1972-1977. Brighton, UK: Harvest Press.

Hilbert, M. (2016). Big Data for Development: A Review of Promises and Challenges. Development Policy Review, 34(1), 135-174. doi:10.1111/dpr.12142 Available at http://ssrn.com/abstract=2205145

Hofmann, J., Katzenbach, C., \& Gollatz, K. (2016) Between coordination and regulation: Finding the governance in Internet governance. New Media \& Society. Advance online publication.

doi:10.1177/1461444816639975

Irani, L. (2015). Difference and Dependence Among Digital Workers: The Case of Amazon Mechanical Turk. South Atlantic Quarterly, 114(1). doi:10.1215/o0382876-2831665

Jørgensen, R.F. (Ed.) (2006) Human Rights in the Global Information Society. Cambridge, MA: MIT Press

Kitchin, R. (2014) The real-time city? Big data and smart urbanism. GeoJournal, 79(1): 1-14. doi:10.1007/s10708-013-9516-8

Klein, H. (2002) ICANN and Internet Governance: Leveraging Technical Coordination to Realize Global Public Policy. The Information Society, 18(3), 193-207. 
doi:10.1080/01972240290074959

Kleinwächter, W. (2000) ICANN between technical mandate and political challenges. Telecommunications Policy, 24(6-7), 553-563. doi:10.1016/So308-5961(oo)ooo37-9

Law, J. (2003). Ordering and Obduracy. Lancaster: Centre for Science Studies, Lancaster University. Available at http://www.comp.lancs.ac.uk/sociology/papers/Law-Orderingand-Obduracy.pdf

Leonardi, P. M. (2012). Materiality, sociomateriality, and socio-technical systems: What do these terms mean? How are they different? Do we need them? In P. M. Leonardi, B. A. Nardi, \& J. Kallinikos (Eds.), Materiality and organizing: Social interaction in a technological world (pp. 25-48). Oxford: Oxford University Press.

Lessig, L. (1999) Code and Other Laws of Cyberspace. New York: Basic Books

Madsen, A., Flyverbom, M., Hilbert, M., \& Ruppert, E. (2016). Big Data: Issues for an International Political Sociology of Data Practices. International Political Sociology, 10(3), 275296. doi:10.1093/ips/olwo10

Mansell, Robin (2012) Imagining the internet: communication, innovation, and governance. Oxford: Oxford University Press.

Mayer-Schönberger, V. \& K. Cukier. (2013). Big Data: A Revolution That Will Transform How We Live, Work, and Think. Boston: Eamon Dolan/Houghton Mifflin Harcourt.

Morozov, E. (2014a). To save everything, click here: the folly of technological solutionism. New York, NY: PublicAffairs.

Morozov, E. (2014b, July 19). The rise of data and the death of politics. The Guardian. Retrieved from

http://www.theguardian.com/technology/2014/jul/20/rise-of-data-death-of-politics-evgeny-m orozov-algorithmic-regulation

Mueller, M. (2002) Ruling the Root: Internet Governance and the Taming of Cyberspace.

Cambridge, MA: MIT Press.

Mueller, M. (2010). Networks and States: The Global Politics of Internet Governance.

Cambridge, MA: MIT Press. doi:10.7551/mitpress/9780262014595.001.0001

Musiani, F. (2015). Practice, Plurality, Performativity, and Plumbing: Internet Governance Research Meets Science and Technology Studies. Science, Technology, \& Human Values, 40(2), 272-286. doi:10.1177/0162243914553803

Musiani, F., Cogburn, D. L., DeNardis, L., Levinson, N. S., \& Nanette, L. S. (Eds.). (2016). The Turn to Infrastructure in Internet Governance. New York: Palgrave Macmillan.

Pasquale, F. (2015) The Black Box Society: The Secret Algorithms That Control Money and Information. Cambridge, MA: Harvard University Press.

Peters, J. D. (2015). The Marvelous Clouds: toward a philosophy of elemental media. Chicago; London: University of Chicago Press. 
Roberts, S.T. (2016). Commercial Content Moderation: Digital Laborers' Dirty Work. In S. U. Noble \& B. M. Tynes (Eds.), Intersectional Internet: Race, Sex, Class and Culture Online. New York: Peter Lang Publishing, Inc.

Ruppert, E. (2011). Population Objects: Interpassive Subjects. Sociology, 45(2), 218-233. doi:10.1177/0038038510394027

Shapiro, G. (2003) Archaeologies of Vision: Foucault and Nietzsche on Seeing and Saying. Chicago: University of Chicago Press.

Singh, J.P., \& Flyverbom, M. (2016) Representing participation in ICT4D projects. Telecommunications Policy, 4O(7), 692-703. doi10.1016/j.telpol.2016.02.003

Stohl, C., Stohl, M., \& Leonardi, P. (2016). Managing Opacity: Information Visibility and the Paradox of Transparency in the Digital Age. International Journal of Communication, 10. Retrieved from http://ijoc.org/index.php/ijoc/article/view/4466

Treem, J. W., \& Leonardi, P. M. (2013). Social Media Use in Organizations: Exploring the Affordances of Visibility, Editability, Persistence, and Association. Annals of the International Communication Association, 36(1), 143-189. doi:10.1080/23808985.2013.11679130

Walters, W. (2012). Governmentality: Critical Encounters. London: Routledge.

Weber, R. (2008). Transparency and the governance of the internet. Computer Law \& Security Review, 24(4), 342-348. doi:10.1016/j.clsr.2008.05.003

Ziewitz, M. (2016). Governing Algorithms: Myth, Mess, and Methods. Science, Technology \& Human Values, 41(1), 3-16. doi:10.1177/0162243915608948

Ziewitz, M. and Petzold, C. (2014) In search of internet governance: Performing order in digitally networked environments. New Media \& Society, 16(2), 306-322.

doi:10.1177/1461444813480118 